\title{
Métodos de preparación de nanopartículas de quitosano: una revisión
}

\author{
Preparation methods of chitosan nanoparticles: a review
}

\begin{abstract}
Francisco J. Caro-León 1,5,*, Luis M. López-Martínez 2,5, Jaime Lizardi-Mendoza', Waldo Argüelles-Monal ${ }^{3}$,Francisco M. Goycoolea-Valencia ${ }^{4}$, Elizabeth Carvajal-Millán', Yolanda L. López-Franco ${ }^{1}$

Centro de Investigación en Alimentación y Desarrollo, A.C. Carretera a Ejido La Victoria Km 0.6, C.P. 83000, Hermosillo, Sonora, México.

2 Universidad de Sonora, Departamento de Investigación en Polímeros y Materiales, Blvd. Luis Encinas y Rosales s/n Col. Centro, C.P. 83000, Hermosillo, Sonora, México.

3 Centro de Investigación en Alimentación y Desarrollo, A.C. Carretera al Varadero Nacional Km. 6.6 Col. Las Playitas, C.P. 85480, Guaymas, Sonora, México.

University of Leeds, School of Food Science and Nutrition, LS2 9JT, Woodhouse Ln, Leeds, United Kingdom.

Universidad Estatal de Sonora, Av. Ley Federal del Trabajo s/n Col. Apolo, C.P. 83100, Hermosillo, Sonora, México.
\end{abstract}

\section{RESUMEN}

El quitosano es un polisacárido natural que ha sido utilizado frecuentemente en el desarrollo de distintos materiales, debido a sus excepcionales propiedades fisicoquímicas y biológicas. Las nanopartículas de quitosano son generalmente producidas por estrategias denominadas de construcción (del inglés "bottom-up"), donde el ensamblado polimérico es promovido por distintas interacciones moleculares. Sin embargo, un grupo de estrategias llamadas de deconstrucción (del inglés "top-down") basadas en la fragmentación de estructuras macroscópicas, han generado un gran interés recientemente como alternativa para la obtención de nanomateriales. El presente trabajo hace una revisión bibliográfica de los resultados obtenidos por distintas investigaciones sobre la producción de sistemas de nanopartículas basadas en quitosano durante las últimas décadas. Las evidencias demostraron que las nanopartículas de quitosano juegan un papel preponderante en la investigación de los nanomateriales poliméricos con aplicaciones biomédicas y farmacéuticas, debido a la gran diversidad de métodos de obtención existentes que determinan las propiedades de los materiales, tales como tamaño de partícula, capacidad de incorporación y liberación de compuestos bioactivos, carga superficial, mucoadhesividad, entre otras.

Palabras clave: quitosano; nanopartículas; construcción; deconstrucción.

\section{ABSTRACT}

Chitosan is a natural polysaccharide which has been frequently used for the development of diverse materials due to its outstanding physicochemical and biological properties. Chitosan nanoparticles are generally produced by "bottom-up" strategies, where polymeric assembling is promoted by various molecular interactions. However, a group of strategies called "top-down", based on the deconstruction of macroscopic structures, has recently generated great interest as an alternative for obtaining nanomaterials. This paper reviews relevant research findings on the production

*Autor para correspondencia: Francisco J. Caro-León

Correo electrónico: javier.caro@estudiantes.ciad.mx

Recibido: 03 de julio de 2018

Aceptado: 18 de abril de 2019 of chitosan-based nanoparticle systems over the last decades. Evidences showed that chitosan nanoparticles play a relevant role in the research of polymeric nanomaterials with biomedical and pharmaceutical applications. This, due to the diversity of production methods which influence the properties of the obtained materials, such as particle size, capacity of incorporation and release of bioactive compounds, surface charge, mucoadhesivity, among others.

Keywords: chitosan; nanoparticles; bottom-up; top-down.

\section{INTRODUCCIÓN}

Actualmente, la producción de nanomateriales de origen polimérico puede clasificarse dentro de dos grandes estrategias: construcción y deconstrucción, conocidas por los términos en inglés "bottom-up" y "top-down", respectivamente. La estrategia de construcción se basa en agregar o acumular moléculas, hasta obtener estructuras en el intervalo de tamaño deseado (orden de los nanómetros). Por su parte, la estrategia de deconstrucción se basa en el fraccionamiento controlado de materiales más grandes con el objetivo de producir los nanomateriales (Canelas et al., 2009; Zhang et al., 2017). Múltiples investigaciones se han abocado en la optimización de las propiedades de las nanopartículas mediante la utilización de metodologías de preparación que promueven una variedad de interacciones inter e intra-moleculares. En este sentido, los biopolímeros han surgido como una opción muy atractiva para la obtención de nanopartículas, debido a su biodegradabilidad y biocompatibilidad. Este grupo incluye derivados naturales y sintéticos de proteínas, polipéptidos y polisacáridos, teniendo el quitosano un papel preponderante en éstos últimos.

El quitosano es un polisacárido con propiedades biológicas excepcionales, tales como mucoadhesividad, biocompatibilidad, biodegradabilidad y baja inmunogenicidad (Bento et al., 2015; Rinaudo, 2006; Rodrigues et al., 2012; Silva et al., 2017; Zhou et al., 2015). Por ello, las nanopartículas de quitosano se han utilizado como un sistema de administración no viral para biomoléculas tales como ácidos nucleicos, 
péptidos y fármacos, administradas por vía oral, nasal, parenteral y a través del colon, entre otras (Anitha et al., 2014; Borges et al., 2008; Bowman y Leong, 2006; Goycoolea et al., 2009; Kim et al., 2007; Liu et al., 2014; Raj et al., 2018).

El estudio de las nanopartículas de quitosano comenzó durante los años noventa en busca de alternativas para sistemas a base de polímeros sintéticos que presentaban estabilidad limitada a la incorporación de proteínas en su estructura (Divya y Jisha, 2018; Garcia-Fuentes y Alonso, 2012). Inicialmente, se obtuvieron nanopartículas de quitosano promoviendo interacciones covalentes entre los grupos amino del polisacárido y grupos hidroxilo de diversos agentes entrecruzantes. Posteriormente, se desarrollaron nanopartículas de quitosano basadas en interacciones iónicas a fin de evitar el uso de solventes, entrecruzantes u otros aditivos potencialmente tóxicos. Por otra parte, investigaciones adicionales exploraron la utilización de las interacciones físicas para la preparación de dichos sistemas, sin embargo, la baja estabilidad de éstos limitó en cierta medida su utilización. Actualmente, las metodologías de deconstrucción se han colocado como una alternativa interesante para producir nanopartículas, ya que se basan principalmente en la fragmentación controlada de materiales macroscópicos del polisacárido. El planteamiento de diferentes procesos de obtención está relacionado con la búsqueda del mejoramiento de características como tamaño, estabilidad, carga superficial y la capacidad de incorporación de principios activos con actividad biológica.

El presente trabajo compila avances recientes en los métodos de obtención de nanopartículas de quitosano enfocándose principalmente en las interacciones que gobiernan cada método y evaluando cuál será su papel en futuras investigaciones.

\section{Estrategias de construcción Producción de nanopartículas por interacciones covalen- tes}

Las interacciones covalentes fueron las primeras exploradas para la producción de nanopartículas de quitosano por Watzke y Dieschbourg en 1994, quienes obtuvieron nanocompositos de quitosano-sílice mediante la reacción de entrecruzamiento de tetrametoxisilano (TMOS) con los grupos hidroxilo del monómero de quitosano. Los métodos de emulsión-entrecruzamiento y micelización inversa se analizarán a continuación.

\section{Emulsión-entrecruzamiento}

El método de obtención de nanopartículas por emulsión-entrecruzamiento involucra la producción de una emulsión de agua en aceite $(\mathrm{W} / \mathrm{O})$ resultado de la mezcla de una solución acuosa de quitosano con una fase orgánica. Posteriormente, un agente de entrecruzamiento es añadido, incrementando la estabilidad de las partículas producto de su afinidad con los grupos funcionales del quitosano. Ohya et al. (1994) reportaron la primera producción de nanopartículas del polisacárido por este método. Dicho grupo de investigación obtuvo nanopartículas esféricas de tamaño promedio de 250 a $300 \mathrm{~nm}$. Para ello, el fármaco y el polisacárido se disolvieron en medio acuoso a pH ligeramente ácido. Posteriormente, una disolución del tensoactivo span 80 en tolueno se añadió a la fase acuosa en agitación magnética constante, formándose una emulsión. Finalmente, otra disolución del entrecruzante glutaraldehído en tolueno y en presencia del tensoactivo se añadió al medio de reacción, lo cual incrementó en gran medida la estabilidad de las nanopartículas. Éstas presentaron la capacidad de incorporar $6 \mathrm{x}$ $10^{-2} \mathrm{mg} / \mathrm{mg}$ del fármaco anticancerígeno 5 -fluorouracilo y su liberación se llevó a cabo de manera controlada, liberándose hasta un $40 \%$ en ocho semanas (Figura 1).

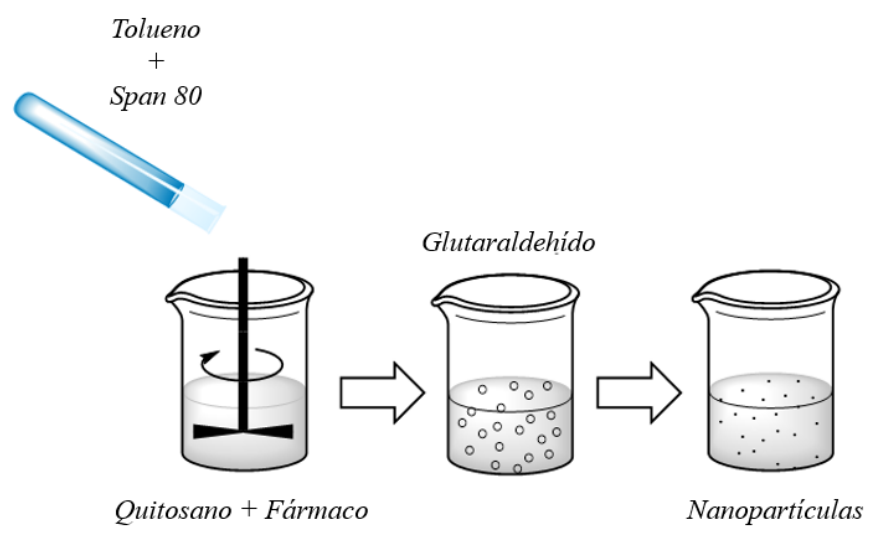

Figura 1. Procedimiento de producción de nanopartículas por emulsiónentrecruzamiento.

Figure 1. Emulsion cross-linking procedure for nanoparticles production.

Investigaciones posteriores reportaron ciertas modificaciones al método, principalmente involucrando la obtención de emulsiones relativamente más complejas. Dichos métodos se han empleado para la producción de nanopartículas con propiedades magnéticas. Para ello, el proceso de preparación inició con una emulsión W/O obtenida por la adición del tensoactivo Triton X-100 a una mezcla de ciclohexano, n-hexanol y ácido clorhídrico $(\mathrm{HCl})$ conteniendo quitosano y $\mathrm{Fe}\left(\mathrm{NH}_{4}\right)_{2}\left(\mathrm{SO}_{4}\right)_{2}$. Al mismo tiempo, otra emulsión W/O conteniendo todo lo señalado anteriormente, pero reemplazando al polisacárido por glutraldehído, se obtuvo mediante el mismo proceso. A fin de promover las propiedades magnéticas en las nanopartículas, una disolución de $\mathrm{NaOH}$ fue añadida a la emulsión del polisacárido y la sal de hierro, obteniéndose precipitados de $\mathrm{Fe}(\mathrm{OH})_{2}$ y del propio polisacárido. Un tratamiento posterior con bajas concentraciones de oxígeno oxida el $\mathrm{Fe}(\mathrm{OH})_{2} a_{\mathrm{Fe}_{3}} \mathrm{O}_{4^{\prime}}$ el cual presentó interesantes propiedades magnéticas. Finalmente, las nanopartículas en suspensión fueron estabilizadas mediante la mezcla de ambas emulsiones en agitación magnética constante. Esta metodología permitió obtener nanopartículas de entre 10 y $50 \mathrm{~nm}$ con potenciales aplicaciones en sistemas de separación de líquidos (Zhi et al., 2006).Jain et al. (2014) obtuvieron nanopartículas de quitosano por este método con la finalidad de aplicarlas como dispositivo biodegradable de liberación controlada 
del fármaco anticancerígeno docetaxel, empleado comúnmente en el tratamiento del cáncer de mama. El proceso de obtención inició, de igual manera, con la obtención de la microemulsión W/O. En este caso, primeramente, se añadió el tensoactivo Triton X-100 a una mezcla compuesta por una solución de docetaxel en ciclohexano, hexanol y la disolución acuosa de quitosano. Paralelamente, se obtuvo otra microemulsión W/O reemplazando la solución de quitosano por una de glutaraldehído. La adición de la emulsión del entrecruzante a la del polímero produjo nanopartículas de morfología esférica con un tamaño promedio menor a 200 $\mathrm{nm}$ y carga superficial positiva (potencial zeta de entre +28.3 y +31.4 mV). La capacidad de incorporación y de carga del fármaco correspondió a 76 y $12 \%$, respectivamente, con liberación del $83 \%$ en las primeras 12 horas de estudio. Las nanopartículas cargadas con docetaxel permitieron inhibir en un $20 \%$ el crecimiento de la línea celular MDA-MB-231 (cáncer de mama) comparadas con el docetaxel libre después de 72 horas de incubación.

Barbari et al. (2017) obtuvieron nanopartículas por interacciones covalentes mediante el método de emulsiónentrecruzamiento empleando al polietilenglicol funcionalizado con grupos carboxílicos terminales (PEG) como agente entrecruzante. Los materiales presentaron interesantes propiedades de hinchamiento en medio acuoso y estabilidad en un amplio rango de pH. El método de obtención permitió producir nanopartículas con un tamaño promedio inferior a $15 \mathrm{~nm}$ en sequedad, con bajos niveles de polidispersidad, morfología esférica y un potencial zeta de $+5 \mathrm{mV}$ (valor relativamente bajo adjudicado a la presencia de cadenas de PEG en la superficie de las nanopartículas). Un péptido con capacidad de penetración celular (CPP) fue conjugado en la superficie de las nanopartículas de quitosano obtenidas, lo que le confirió la propiedad de penetrar monocapas de células Caco-2. En dicho estudio se incorporó insulina a los nanomateriales conjugados con CPP, presentando un aumento en el porcentaje de translocación del péptido del $18 \%$ en comparación con soluciones simples en cultivo. La incorporación del péptido ocasionó un incremento del potencial zeta a $+32 \mathrm{mV}$ debido a la presencia de aminoácidos cargados positivamente como arginina y lisina.

Los más recientes estudios empleando la técnica de emulsión-entrecruzamiento han sido reportados por Hood et al. (2018) quienes obtuvieron suspensiones estables de nanopartículas de quitosano, las cuales fueron utilizadas como sistema sustrato para la cristalización de diversos polimorfos de carbonato de calcio $\left(\mathrm{CaCO}_{3}\right)$. Este quitosano bioinspirado se entrecruzó con 1,4-Butanodiol diglicidil éter, produciéndose nanopartículas con un diámetro hidrodinámico de 100-350 nm con capacidad de hinchamiento sensible a pH y potencial zeta de $+40 \mathrm{mV}$ (indicando buena estabilidad).

\section{Micelización inversa}

La micelización inversa es un método de obtención de nanopartículas caracterizado por la producción de emulsiones de tipo W/O a base de surfactantes lipofílicos disueltos en medio orgánico, principalmente el bis-(2-etilhexil) sulfosuccinato sódico (AOT). Al igual que con el proceso de emulsión ordinaria, el glutaraldehído es el agente entrecruzante más utilizado, aunque, tomando en consideración su toxicidad, nuevas alternativas han sido probadas, como por ejemplo la genipina, de origen biológico. El procedimiento de micelización inversa permite la obtención de nanopartículas con baja polidispersidad con tamaños promedio inferiores a $100 \mathrm{~nm}$. La especificidad en los tamaños se debe principalmente al comportamiento dinámico durante el proceso de producción; las gotas minúsculas de la emulsión están en movimiento browniano continuo, sometiéndose a un ciclo de coalescencia y separación en cuestión de microsegundos. Mediante el método de micelización inversa, un conjugado de dextrano- doxorubicina (DEX-DXR) fue incorporada a nanopartículas de quitosano. Primero, se obtiene una solución de AOT en n-hexano, a la cual posteriormente le fue añadida una fase compuesta por la solución acuosa del polisacárido, el conjugado DEX-DXR, $\mathrm{NH}_{4} \mathrm{NO}_{3}$ y la solución del entrecruzante glutaraldehído. Posteriormente se evaporó el solvente orgánico lo cual permitió la obtención de nanopartículas con un diámetro promedio de $100 \mathrm{~nm}$. Dichas nanopartículas presentaron un incremento en la actividad antitumoral comparada con soluciones de DXR y el complejo DEX-DXR libre (sin incluir en nanopartículas) evaluadas en macrófagos tumorales J774A.1 (Mitra et al., 2001).

El método de micelización inversa fue empleado por Chua et al. (2012) para obtener nanopartículas transportadoras de vacunas basadas en la hormona luteinizante, llevando a cabo ciertas modificaciones al método inicialmente reportado. En dicha investigación, la micelización inversa se obtuvo añadiendo la disolución acuosa de polisacárido a una fase orgánica compuesta de parafina liquida con diferentes proporciones de la mezcla de los tensoactivos tween 80 y span 80 en agitación magnética constante. Posteriormente, se llevó a cabo la adición de glutaraldehído saturado con tolueno para promover el entrecruzamiento. Las condiciones de obtención demostraron que la velocidad de agitación y la proporción de los tensoactivos determinaron el tamaño de las nanopartículas, obteniéndose las de menores dimensiones en un rango de 113 a $213 \mathrm{~nm}$. Las partículas fueron funcionalizadas con grupos cloro acetilo para promover la unión covalente con grupos tiol presentes en antígenos proteicos (los cuales conforman una vacuna compuesta del péptido sintético derivado de la hormona luteinizante conjugado covalentemente a una proteína transportadora), lo cual permitió la incorporación de hasta un $20 \%$ de antígeno a los sistemas. La microscopia confocal indicó que una mayor proporción de antígenos estuvieron concentrados en la superficie de las nanopartículas y que éstos presentaban la capacidad de inducir la formación de anticuerpos específicos.

Orellano et al. (2017) obtuvieron nanopartículas de quitosano entrecruzadas con glutaraldehído utilizando micelización inversa, partiendo de una solución de AOT en nheptano. Las nanopartículas obtenidas presentaron bajos niveles de polidispersidad y su tamaño dependió en gran 
medida de la concentración de los reactantes, grado de entrecruzamiento $y$, mayoritariamente, de la cantidad de agua presente en las micelas inversas que funcionaron como micro-reactores. La eficiencia en la metodología reportada se confirmó al comparar los tamaños de las nanopartículas obtenidas tanto en el medio de micelización inversa como en un medio compuesto únicamente por agua. Para el primer caso, el tamaño obtenido fue de aproximadamente $90 \mathrm{~nm}$, mientras que para el segundo sistema las partículas presentaron tamaños superiores a $130000 \mathrm{~nm}$. Los resultados obtenidos se relacionan con el hecho de que las cadenas de quitosano confinadas en las micelas inversas orientan sus grupos $\mathrm{NH}_{2}$ cerca de la interface aniónica, lo que favorece su ordenamiento y las reacciones de entrecruzamiento, lográndose la obtención de tamaños de partícula más pequeños y homogéneos.

Recientemente, Riegger et al. (2018) investigaron el impacto de la concentración de glutaraldehído y el peso molecular de quitosanos altamente desacetilados en la obtención de nanopartículas por micelización inversa, así como su capacidad como adsorbente de diclofenaco. Se demostró que con una proporción 1:1 de glutaraldehído y amina primaria del polisacárido fue posible obtener, de forma reproducible, nanopartículas esféricas con baja polidispersidad, con un alto rendimiento y tamaños inferiores a $200 \mathrm{~nm}$. Se determinó una capacidad de adsorción de hasta $352 \mathrm{mg} / \mathrm{g}$ de diclofenaco, mostrándose una mayor adsorción en las nanopartículas (en todas las condiciones probadas) comparada con la del polisacárido no tratado.

Las metodologías basadas en interacciones covalentes han sido empleadas para producir nanopartículas de quitosano con interesantes aplicaciones, como por ejemplo, el transporte de moléculas con actividad biológica. A su vez, el proceso de micelización inversa ha permitido la producción de nanopartículas de tamaño promedio inferior a $100 \mathrm{~nm}$. Si bien todas estas contribuciones han sido muy importantes, el uso de disolventes orgánicos y aditivos tóxicos como el glutaraldehído han provocado un descenso en el interés en la investigación de los métodos citados, promoviendo la búsqueda de alternativas que propicien la biocompatibilidad de los sistemas.

\section{Producción de nanopartículas por interacciones iónicas}

Estos métodos se basan en la agregación de las moléculas poliméricas producto de interacciones de tipo electrostáticas. Podemos dividir la producción de nanopartículas a base de interacciones iónicas en dos grandes grupos: la gelificación ionotrópica y la complejación polielectrolítica.

\section{Gelificación ionotrópica}

En la metodología de gelificación ionotrópica, las nanopartículas son formadas mediante agregación de las moléculas poliméricas producto de la interacción del polisacárido de carga positiva y especies cargadas negativamente. El tripolifosfato de sodio (TPP) es el agente entrecruzante más común para producir nanopartículas de quitosano por gelificación ionotrópica. La adición de TPP a una solución de quitosano, en condiciones apropiadas de temperatura y agitación produce las nanopartículas debido a la interacción de cargas opuestas (Calvo et al., 1997) (ver la Figura 2).

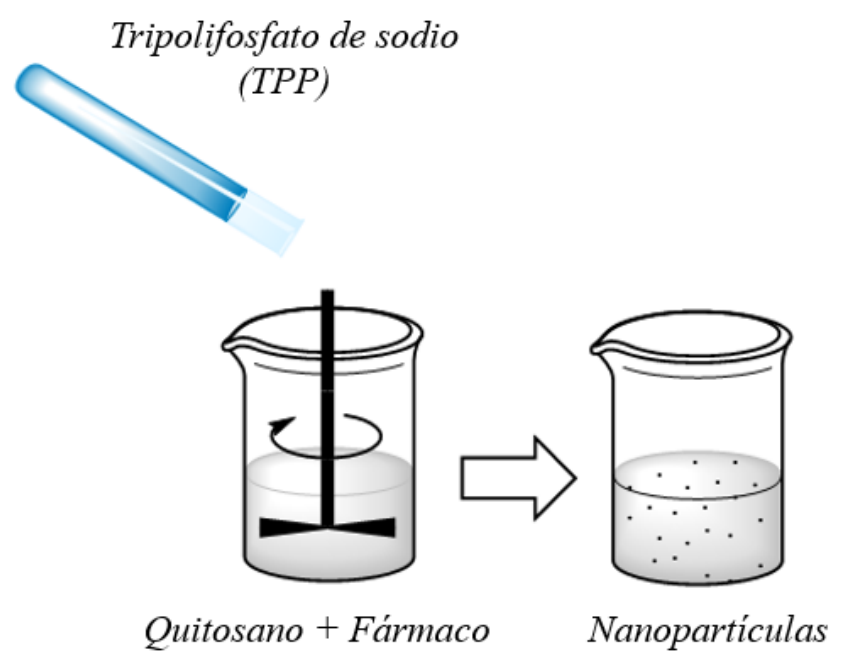

Figura 2. Procedimiento de producción de nanopartículas por gelificación ionotrópica.

Figure 2. Ionic gelation procedure for nanoparticles production.

Empleando la técnica de gelificación ionotrópica, se han obtenido nanopartículas de quitosano-alginato cargadas con insulina para administración nasal. El proceso de producción incluye la formación espontánea de las nanopartículas al mezclar rápidamente una solución de quitosano en medio acuoso y una solución de TPP/alginato/insulina en agitación magnética constante. El tamaño promedio de las nanopartículas fue de 260 a $525 \mathrm{~nm}$, con potencial zeta de entre +20 y $+60 \mathrm{mV}$ (dependiendo de la proporción de alginato). La eficiencia de incorporación obtenida estuvo en el rango de 40-50\%, independiente de la concentración de alginato. Los sistemas liberaron altas concentraciones de insulina en tiempos cortos (efecto burst); más del $80 \%$ del polipéptido fue liberado dentro de los primeros 20 minutos, alcanzándose el 100\% en 120 min. Este comportamiento fue asociado a la interacción iónica débil de la insulina con el polisacárido. Las nanopartículas cargadas mejoraron la absorción sistémica de insulina después de la administración nasal en un modelo animal de conejo (Goycoolea et al., 2009).

Bagre et al. (2013) obtuvieron nanopartículas de quitosano para la administración oral de enoxaparina también por el método de gelificación ionotrópica, añadiendo al fármaco en la fase acuosa del polisacárido durante el proceso de síntesis. Una vez obtenidas, las nanopartículas fueron revestidas con alginato, obteniéndose un tamaño promedio de $213 \mathrm{~nm}$ y potencial zeta de $+39 \mathrm{mV}$. Dicho recubrimiento permitió aumentar la tasa de liberación controlada de la enoxaparina incorporada, demostrándose que un $75 \%$ del fármaco fue capaz de atravesar el epitelio del intestino en un modelo de saco intestinal evertido. Además, se pudo demostrar que las 
nanopartículas aumentaron la concentración plasmática del fármaco y redujeron la formación de trombos en un modelo de trombosis venosa en ratas.

Mali et al. (2015) obtuvieron una formulación de nanopartículas de quitosano cargadas con serratiopeptidasa para administración oral. El tamaño promedio de los sistemas se encontraba en un rango de $400-600 \mathrm{~nm}$ con una eficiencia de asociación del $80 \%$ y capacidad de liberación controlada por 24 horas. La actividad antiinflamatoria in vivo se determinó en un modelo de edema de pata de rata y mostró un efecto antiinflamatorio prolongado durante 32 horas.

Una investigación reciente se abocó a estandarizar condiciones tales como concentración y proporción de los reactantes, peso molecular del quitosano y $\mathrm{pH}$, a fin de generar nanopartículas por gelificación ionotrópica de menor tamaño y polidispersidad, reportándose en los resultados del estudio tamaños promedio menores a $90 \mathrm{~nm}$ y potencial zeta de $+30 \mathrm{mV}$ (Sullivan et al., 2018). Esta clase de reportes demuestran la importancia de la metodología de gelificación ionotrópica, la cual es la más empleada en la actualidad debido a la simplicidad en las condiciones experimentales y al hecho de que no se requiere de la utilización de aditivos tóxicos.

Una importante variación del método ordinario de gelificación ionotrópica es el método de gelificaciónpolimerización. Dicho método involucra la producción de nanopartículas de quitosano mediante la interacción electrostática de monómero de ácido acrílico o metacrílico con el quitosano en solución acuosa. Las interacciones iónicas entre las cadenas del polímero cargadas positivamente con el monómero aniónico son seguidas por un proceso de polimerización en condiciones controladas (Divya y Jisha, 2018; Grenha, 2012).

Empleando este tipo de metodología, se produjeron nanopartículas de quitosano- poliácido acrílico cargadas con péptido de seda (silk peptide). El proceso de obtención involucra la disolución del polisacárido en una solución acuosa de ácido acrílico. Posteriormente, persulfato de potasio fue añadido a fin de promover el proceso de polimerización, el cual se llevó a cabo en condiciones controladas de temperatura y atmosfera (nitrógeno). Los sistemas obtenidos mostraron un tamaño en el rango de 50 a $400 \mathrm{~nm}$ y potencial zeta de entre +20 y $+30 \mathrm{mV}$. El péptido fue incorporado al sistema al añadirse a la suspensión de nanopartículas e incubarse por 48 horas, obteniéndose una liberación continua in vitro durante 10 días dependiendo del pH del medio (Hu et al., 2002).

Otros estudios reportaron la obtención de nanopartículas de quitosano y quitosano tiolado-poli (isobutil cianoacrilato) mediante el método de gelificación-polimerización, para evaluar su potencial aplicación como bioadhesivo. La polimerización del monómero se llevó a cabo en este caso en una solución del polisacárido en ácido nítrico. A partir de esto, se pudo demostrar que la presencia de quitosano en las nanopartículas permite incrementar la mucoadhesividad en las superficies de la mucosa intestinal de rata, debido a la presencia de múltiples interacciones no covalentes. Las na- nopartículas tuvieron diferentes tamaños dentro del rango de 181 a $548 \mathrm{~nm}$, el cual fue dependiente del peso molecular del quitosano empleado. El potencial zeta de los sistemas decreció a medida que la proporción del quitosano tiolado se incrementó, producto de la reducción de la viscosidad en la estructura del gel por la aparición de múltiples enlaces disulfuro. Por otra parte, los grupos tiol en la superficie de las nanopartículas promovieron la formación de enlaces covalentes con los residuos de cisteína de las glicoproteínas mucoides, incrementando de igual manera la mucoadhesividad (Bravo-Osuna et al., 2007).

También, se ha reportado la obtención de nanopartículas de quitosano/poli ácido metacrílico a base de gelificación-polimerización, con capacidad de eliminar iones $\mathrm{Co}(\mathrm{II}), \mathrm{Ni}(\mathrm{II})$ y $\mathrm{Cu}$ (II) de soluciones acuosas utilizando la técnica de adsorción por lotes (Shaker, 2015). El tamaño promedio de las nanopartículas fue de $120 \mathrm{~nm}$ con recuperaciones de los iones metálicos adsorbidos de hasta $90 \%$. El potencial zeta presentó valores positivos a $\mathrm{pH} \approx 1$, debido a las aminas protonadas y a los grupos hidroxilo. Con el aumento del $\mathrm{pH}$, el potencial zeta disminuyó por la desprotonación de los grupos amino y la conversión de los grupos carboxílicos en carboxilato. La carga negativa de las nanopartículas se incrementó a $\mathrm{pH}>4.5$, debido a la ionización de grupos carboxilato y a la neutralización de los grupos amino. Siguiendo con la aplicación mencionada, Ge et al., 2016 obtuvieron nanopartículas de quitosano/poliácido acrílico utilizando al $\mathrm{Pb}^{2+}$ como ion de prueba. Las nanopartículas obtenidas presentaron un diámetro promedio de $200 \mathrm{~nm}$ con una capacidad de adsorción del ion de $734 \mathrm{mg} / \mathrm{g}$, lo cual supera claramente la capacidad de otros adsorbentes específicos para $\mathrm{Pb}^{2+}$ actualmente existentes. Cabe señalar que los autores de esta última investigación emplearon glutaraldehído con la final de incrementar la estabilidad del sistema, sin embargo, la formación de las nanopartículas en suspensión obedece a interacciones de tipo electrostáticas entre el polisacárido y el poliácido acrílico.

\section{Complejación polielectrolítica}

La complejación de polielectrolítica es otro método para producir nanopartículas de quitosano por interacciones iónicas. Este método se basa en el enlace iónico de los grupos cargados positivamente del quitosano y macromoléculas aniónicas, dentro de las cuales se encuentran algunos polisacáridos (sulfato de dextrano, ciclodextrinas, pectinas y carragenina), péptidos (insulina), ADN y ácido hialurónico (Grenha et al., 2010; Birch y Schiffman, 2014; de la Fuente et al., 2008; Delair, 2011; Fülöp et al., 2014; Lavertu et al., 2006; Nam et al., 2010; Wang et al., 2017).Empleando la metodología citada, se reportó la obtención de sistemas de nanopartículas de quitosano/carragenina con capacidad de incorporar ovoalbúmina. Las interacciones iónicas entre el quitosano positivamente cargado y los aniones de carragenina en medio acuoso produjeron nanopartículas de tamaño promedio de 350-650 $\mathrm{nm}$ y potencial zeta de entre +50 y $+60 \mathrm{mV}$, con un $17 \%$ de capacidad de carga de proteína y una liberación controlada 
de hasta 3 semanas. Una alta biocompatibilidad de las nanopartículas fue demostrada en un modelo de fibroblastos L929 (Grenha et al., 2010).

Por otra parte, se han obtenido nanopartículas de derivados de quitosano conjugadas con folato, utilizando carboximetilquitosano modificado con ácido fólico y clorhidrato de quitosano como entrecruzante. El proceso de obtención inicia al generar un enlace amida entre el folato y el carboximetilquitosano mediante reacción con 1-etil-3-(3dimetilaminopropil)carbodiimida (EDC). Posteriormente, se produce el entrecruzamiento iónico entre los grupos amino cargados positivamente del clorhidrato de quitosano y los grupos carboximetilo cargados negativamente del complejo ácido fólico-carboximetilquitosano, a fin de producir nanopartículas en suspensión acuosa. La morfología obtenida para estas nanopartículas fue de tipo esférica con un tamaño promedio de $400 \mathrm{~nm}$ con potencial zeta positivo de +36 $\mathrm{mV}$. Las nanopartículas alcanzaron un $75 \%$ de eficiencia de encapsulación de catequinas de tipo EGCG en su estructura, las cuales presentan cierta actividad antitumoral (Liang et al., 2014).Estudios posteriores reportaron la preparación de nanopartículas metaestables a partir de quitosano y sulfobutil éter $\beta$-ciclodextrina para incorporar hidrocortisona por complejación polielectrolítica. Los grupos amino protonados del quitosano reaccionaron con los grupos aniónicos polivalentes de la ciclodextrina funcionalizada, produciéndose nanopartículas de diámetros de entre los 200 a 1000 nm (el tamaño fue controlado por la relación molar de los polisacáridos). La eficiencia de encapsulación para dichas nanopartículas fue superior al $30 \%$ con cerca del $35 \%$ de liberación del principio activo en las primeras 12 horas (Fülöp et al., 2014).

En los últimos años se han llevado a cabo investigaciones a fin de producir sistemas de nanopartículas de quitosano basados en interacciones electrostáticas con derivados de ADN (cargados negativamente). Por ejemplo, Wang et al., 2017 emplearon la complejación de polielectrolitos para obtener un sistema vector para el compuesto carotenoide con propiedades antioxidantes astaxantina, a base de nanopartículas poliméricas de quitosano-ADN. El ácido nucleico fue obtenido de esperma de salmón. Las nanopartículas presentaron un tamaño promedio de $211 \mathrm{~nm}$ con capacidad de incorporar alrededor de $65 \mu \mathrm{g} / \mathrm{mL}$ del compuesto bioactivo, lo cual permitió incrementar dispersabilidad de la astaxantina en agua. Por otra parte, los autores demostraron que el carotenoide incorporado en las nanopartículas aumentó la viabilidad de células expuestas a la actividad de $\mathrm{H}_{2} \mathrm{O}_{2}$ en un $12 \%$ y permitió disminuir al doble la actividad de algunas especies reactivas de oxígeno.

Los métodos basados en interacciones iónicas se han posicionado como la primera opción para producir nanopartículas de quitosano debido a que el proceso completo se realiza en un ambiente acuoso, utilizando condiciones no agresivas y de manera espontánea, además que se ha demostrado que las nanopartículas obtenidas por dichos métodos contribuyen a mejorar la viabilidad celular (Divya y Jisha, 2018; Li et al., 2009; Vimal et al., 2013).

\section{Producción de nanopartículas por interacciones físicas}

En los métodos basados en interacciones físicas la agregación de las moléculas de polímero ocurre debido a procesos de desolvatación, interacciones hidrofóbicas-hidrofílicas o a la acción de moléculas estabilizantes; existen tres principales métodos para la obtención de nanopartículas de quitosano mediante interacciones físicas: coalescencia de gotas de emulsión, desolvatación y emulsión-difusión de solvente, cuyas características se mencionarán en las siguientes secciones.

\section{Coalescencia de gotas de emulsión}

Las primeras investigaciones sobre el empleo de la técnica coalescencia de gotas de emulsión reportaron la obtención de nanopartículas de quitosano incorporando ácido gadopentético y su aplicación como una terapia alternativa contra el cáncer. El proceso de preparación incluye la adición de una solución de quitosano/ácido gadopentético a parafina líquida que contiene el agente emulsificante Arlacel $C$ (sesquioleato de sorbitan) bajo agitación magnética, con lo que se forma una emulsión W/O. Además, y de manera paralela, se obtuvo otra emulsión W/O con $\mathrm{NaOH}$ en parafina líquida. La producción de las nanopartículas de quitosano fue producto de la mezcla de ambas emulsiones debido a la acción del $\mathrm{NaOH}$ que neutraliza el pH de la solución del polímero, produciendo su agregación y precipitación. Esta metodología permitió la obtención de nanopartículas de 450 nm con una eficiencia de encapsulación de $45 \%$ de fármaco, liberándose el $90 \%$ de éste en 24 horas. La encapsulación del fármaco en las nanopartículas permitió incrementar en casi un $90 \%$ su retención en tejido tumoral comparado con el ácido gadopentético libre (Tokumitsu et al., 1999). La Figura 3 resume la producción de nanopartículas por coalescencia de gotas de emulsión.

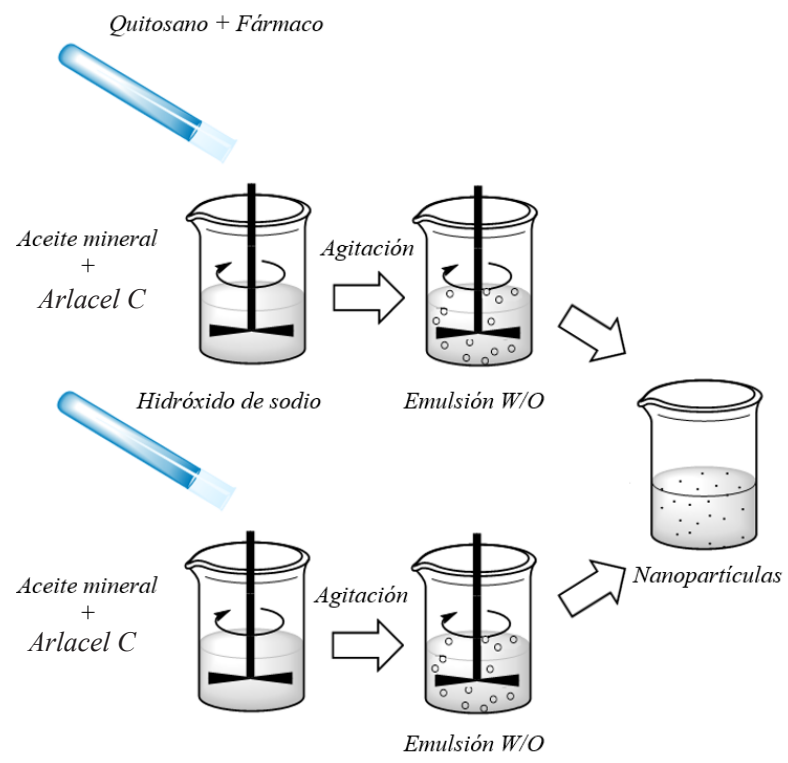

Figura 3. Procedimiento de producción de nanopartículas por coalescencia de gotas de emulsión.

Figure 3. Emulsion droplet coalescence procedure for nanoparticles production. 
Anto-Shering et al. en 2011, obtuvieron nanopartículas de quitosano aplicadas como vectores para 5 -fluorouracilo. En dicha investigación, se obtuvo una liberación máxima del fármaco a las 12 horas. Recientemente, se han llevado a cabo investigaciones adicionales con el mismo fármaco a fin de estudiar posibles alternativas en el método preparación. En ese sentido, Cavalli et al. (2014) obtuvieron nanopartículas cargadas con 5-fluoroacilo mediante el método de coalescencia de gotas de emulsión con algunas variaciones. Para garantizar la reproducibilidad del proceso de preparación, se utilizó una técnica semiautomática basada en una bomba de rodillo. El tamaño promedio de las nanopartículas fue de $200 \mathrm{~nm}$ con una eficiencia de encapsulación del 70\%. El estudio de liberación in vitro mostró que solo un $10 \%$ del 5-fluoroacilo era liberado de los sistemas después de 3 horas. Estas nanopartículas mostraron una importante capacidad para limitar la proliferación de células tumorales al reducir su adhesión a células endoteliales de vena umbilical humana.

\section{Desolvatación}

El método de desolvatación es el segundo procedimiento basado en interacciones físicas para obtener nanopartículas de quitosano. Este método implica la adición de un agente precipitante a una solución acuosa del polisacárido para provocar la disminución de su solubilidad mediante la generación de interacciones entre las moléculas de disolvente y las del agente precipitante, siendo el sulfato de sodio el más utilizado. Por otra parte, se ha reportado que la utilización de antisolventes miscibles en agua permite también la obtención de nanopartículas de quitosano en suspensión, debido a que el medio acuoso presenta más afinidad con el no-solvente que con el polisacárido, lo que promueve la precipitación de éste último (este método también es conocido como nanoprecipitación o de diálisis) (Berthold et al., 1996; Mao et al., 2001; Martínez-Rivas et al., 2017; Tian y Groves, 1999).Empleando el método de desolvatación se obtuvo un sistema de nanopartículas de quitosano cargadas con ovoalbúmina y recubiertas con alginato. El método de obtención se basa en la adición de una solución de sulfato de sodio a una solución acuosa de quitosano en presencia del tensoactivo Tween 80 bajo sonicación. Posteriormente, las nanopartículas obtenidas se llevaron a una solución de alginato de sodio en agitación magnética constante a fin de recubrirlas. Los nanomateriales tenían un tamaño promedio de $684 \mathrm{~nm}$ con alto índice de polidispersidad. El potencial zeta de las nanopartículas fue de $+37 \mathrm{mV}$, sin embargo, el recubrimiento de alginato contribuyó a que el valor decreciera, llegando incluso a $-34 \mathrm{mV}$. El proceso de recubrimiento fue muy importante debido a que su optimización permitió obtener una capacidad de encapsulación del 35\% y prevenir la liberación de la ovoalbúmina en tiempos cortos en un fluido intestinal simulado a temperatura fisiológica (Borges et al., 2005).Kim et al. (2008) obtuvieron nanopartículas de ácido colánico-glicol quitosano por el método de desolvatación (mencionado en la publicación como método de diálisis) incorporando al fármaco anticancerígeno cisplatino. En dicha investigación, se reportó la obtención de un derivado del polisacárido compuesto de ácido colánico y glicol quitosano, con la finalidad de incrementar el carácter hidrófobo del polímero. Para producir las nanopartículas, una solución del derivado fue dializada en una mezcla 1:1 de metanol/ agua en presencia del cisplatino, con lo que se produjo la nanoprecipitación del polisacárido. El tamaño promedio de partícula fue de $300-500 \mathrm{~nm}$ con eficiencia de carga de $80 \%$. Las nanopartículas presentaron capacidad de acumulación en tejidos tumorales en un modelo murino, producto de su persistencia prolongada en circulación e incremento en la permeabilidad y retención celular.

Luque-Alcaraz et al. (2012) reportaron la obtención de nanopartículas cargadas con nobiletina, una flavona polimetoxilada, por medio de desolvatación empleando metanol como antisolvente. Las partículas resultantes presentaron un diámetro promedio de $650 \mathrm{~nm}$ y las eficiencias de asociación y de encapsulación fueron de 69 y 7\%, respectivamente. El método de obtención se basa en la transferencia, a través de una bomba peristáltica, de una solución de quitosano a la fase orgánica conteniendo a la flavona en disolución. Mediante espectroscopia de infrarrojo fue posible determinar la aparición de enlaces imida vía base de schiff entre el grupo carboxílico de la flavona y los grupos amino del quitosano. La nobiletina incorporada en las nanopartículas presentó una considerable inhibición de células cancerosas RAW 264.7, superando la capacidad de la flavona libre $\left(\mathrm{IC}_{50}\right.$ de 8.3 y 80 $\mu \mathrm{g} / \mathrm{mL}$, respectivamente).

Jiang et al. (2018) obtuvieron nanopartículas de quitosano por desolvatación con el objetivo de superar algunas limitaciones del método de gelificación ionotrópica tales como baja estabilidad, baja capacidad de incorporación de fármacos hidrófobos y bajo rendimiento en la formación de las nanopartículas. Para obtener los sistemas, una fase orgánica compuesta por acetona se transfirió a una solución del polisacárido en medio buffer a pH 3.5, empleando posteriormente ultracentrifugación y resuspensión en medio acuoso. Los autores reportaron que su metodología permitió obtener nanopartículas de $196 \mathrm{~nm}$ con rendimiento de prácticamente del $100 \%$ y potencial zeta de $+24 \mathrm{mV}$. Además, se pudo demostrar que la eficiencia de encapsulación para un fármaco modelo (paclitaxel) fue sustancialmente superior a la obtenida en nanopartículas producidas por gelificación ionotrópica (9.8 contra $0.43 \%$, respectivamente). Las nanopartículas no presentaron citotoxicidad significativa en cultivo de células de cáncer de mama MCF-7, dentro de concentraciones de 20 a $1000 \mu \mathrm{g} / \mathrm{mL}$.

\section{Emulsión-difusión de solvente}

La emulsión-difusión de solvente es otro método basado en interacciones físicas. Este método implica la adición de una fase orgánica compuesta de cloruro de metilo y acetona, a una solución acuosa de quitosano con un agente estabilizador en agitación. Esto produce la formación de una emulsión O/W que posteriormente se somete a homogeneización a alta presión. Subsecuentemente, la fase 
orgánica se elimina reduciendo la presión a temperatura ambiente. En esta etapa, la acetona difunde en la fase acuosa, disminuyendo la solubilidad del polímero y produciendo su precipitación, dando como resultado la formación de las nanopartículas (Borges et al., 2008; Niwa et al., 1994; PiñónSegundo et al., 2018).

El-Shabouri, 2002 obtuvieron nanopartículas de quitosano incorporando ciclosporina-A, un fármaco con pobre solubilidad en agua, usando lecitina y poloxamer 188 como emulsificantes. Primeramente, se obtuvo una solución del fármaco y lecitina en cloruro de metilo, para posteriormente mezclar dicha solución con acetona. La fase resultante se transfirió a una solución acuosa de quitosano en condiciones ácidas y en presencia también del poloxamer 188. El cloruro presente en la suspensión se eliminó empleando rotaevaporación, para posteriormente ser reemplazado por agua. Las nanopartículas presentaron tamaños promedio en el rango de 104-148 nm dependiendo de las condiciones experimentales, con una eficiencia de carga superior al 90\%. Estudios adicionales permitieron demostrar un aumento del $73 \%$ en la biodisponibilidad relativa de la ciclosporina-A incorporada en las nanopartículas comparada con una microemulsión comercial del fármaco.

Esta misma metodología fue empleada por Kumar et al. (2016) para producir una formulación del fármaco ocular levofloxacina, reemplazando al diclorometano por cloroformo e incorporando al fármaco en la fase acuosa en condiciones ácidas. La eficiencia de encapsulación y eficiencia de carga fue superior al 90\%, produciéndose nanopartículas de morfología esférica.

\section{Estrategias de deconstrucción}

Con el objetivo de obtener alternativas a las estrategias de construcción para la producción de nanopartículas de quitosano, las metodologías deconstruccion han sido exploradas a fin de evitar la utilización de agentes entrecruzantes y aditivos potencialmente tóxicos que podrían limitar las aplicaciones biológicas de los sistemas. Las estrategias de deconstrucción se basan en la producción de nanomateriales a partir de la desintegración controlada de una superestructura principal. Existen pocos informes sobre la preparación de nanopartículas y nanofibrillas (también conocidos como nanobigotes, del inglés nanowhiskers) mediante estas metodologías y el estudio de sus potenciales aplicaciones es aún incipiente (Canelas et al., 2009; Chantarasataporn et al., 2014; Pereira et al., 2014; Wijesena et al., 2015). Inicialmente, se realizaron investigaciones abocadas en obtener nanofibras de quitosano mediante la reducción de tamaño de polvos de quitosano suspendidos en medio acuoso por molienda en húmedo y homogeneización a alta presión (Liu et al., 2011). El proceso incluyó la suspensión de los polvos en agua destilada para posteriormente forzar su paso por una máquina de molienda en húmedo con una abertura de $0.2 \mathrm{~mm}$. Luego, la suspensión se transfirió a un tanque de almacenamiento de acero inoxidable equipado con dispositivos denominados cámaras de interacción que permitieron la homogeniza- ción de las dimensiones de las fibras del polisacárido en condiciones de alta presión. Las partículas macroscópicas de quitosano fueron efectivamente reducidas a nanofibras mediante el rompimiento de las interacciones presentes en la estructura cristalina por acción de la fuerza mecánica. Los sistemas obtenidos presentaron tamaño de partícula promedio de alrededor de $50 \mathrm{~nm}$, formadas a su vez, por manojos de nanofibrillas de diámetro de 1-5 nm. La investigación mencionada representó un avance importante en el estudio de la aplicación de las metodologías de deconstrucción. El potencial zeta de las partículas suspendidas presentó valores positivos, aunque dicho valor se redujo desde $+35 \mathrm{a}+7.5 \mathrm{mV}$ a medida que el $\mathrm{pH}$ del medio se incrementó de 4 a 8 (ver la Figura 4).

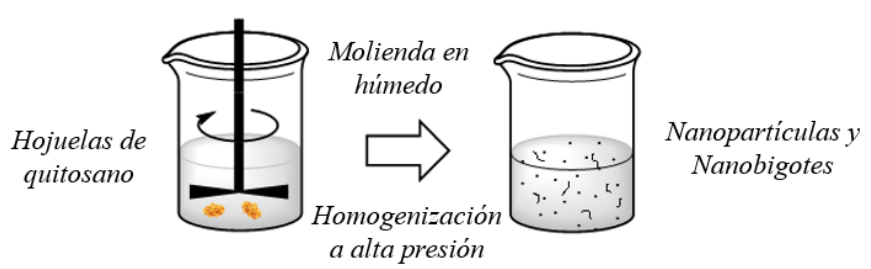

Figura 4. Ejemplo del procedimiento de producción de deconstrucción de nanopartículas.

Figure 4. Example of the top-down nanoparticles production procedure.

Investigaciones posteriores reportaron la obtención de materiales denominados nanofibrillas (nanowhiskers) con núcleo de quitina y recubrimientos de quitosano, producidos por desacetilación superficial. El proceso de obtención inició con la producción de las nanofibrillas a base de quitina mediante hidrólisis con $\mathrm{HCl} 3 \mathrm{~N}$ en alta temperatura y en agitación constante. Posteriormente se llevaron a cabo diversos procesos de centrifugación y resuspensión. El tratamiento de las nanofibrillas de quitina con $\mathrm{NaOH}$ al $50 \%$ a $50^{\circ} \mathrm{C}$ permitió la desacetilación del polisacárido dando como resultado la presencia de quitosano principalmente en la superficie como lo mostraron resultados de difracción de rayos $X$, espectroscopia de infrarrojo y potencial zeta, el cual disminuyó su valor de $+30 \mathrm{a}+20 \mathrm{mV}$ a pH por encima de 3. Estas variaciones se tradujeron en una disminución de la estabilidad de los sistemas promoviendo su agregación, posiblemente debido a un exceso de contraiones causantes de neutralización de las repulsiones electrostáticas. Los mencionados estudios permitieron confirmar que el núcleo de los materiales retenía en gran medida las propiedades cristalinas de la quitina sin verse afectadas por la reacción de desacetilación. Las nanofibrillas presentaron en promedio un tamaño de $247 \mathrm{~nm}$ de largo, $15 \mathrm{~nm}$ de ancho y un espesor de hasta $12 \mathrm{~nm}$ (Pereira et al., 2014).Tomando en cuenta estos antecedentes, se ha reportado recientemente una estrategia de deconstrucción efectiva para producir no solo nanofibriIlas sino también nanopartículas de quitosano utilizando un método asistido por ultrasonido. Inicialmente, hojuelas de quitina de caparazón de cangrejo fueron tratadas con $\mathrm{NaOH}$ y $\mathrm{HCl}$ a fin de purificar al polisacárido. Las hojuelas fueron 
posteriormente expuestas a ultrasonido con una frecuencia de $24 \mathrm{kHz}$ y $360 \mathrm{~W}$ de potencia. Las nanofibras obtenidas fueron desacetiladas con $\mathrm{NaOH}$ en alta temperatura. Como resultado se obtuvo una mezcla de nanofibras y nanopartículas de quitosano, las cuales fueron separadas mediante ultrasonicación y centrifugación, para posteriormente filtrar la suspensión por gravedad a través de filtros de celulosa. El filtrado presentó una mayor proporción de nanopartículas mientras que el residuo estuvo compuesto en su mayoría por nanofibras. Estudios por microscopia electrónica de transmisión demostraron que las nanopartículas tenían morfología esferoide de diámetro promedio de $300 \mathrm{~nm}$ que, a su vez, estaban formadas por la aglomeración de nanopartículas más pequeñas de $25 \mathrm{~nm}$. Por otra parte, las nanofibras de quitosano presentaron un diámetro menor a $100 \mathrm{~nm}$ y una longitud de alrededor de $3 \mathrm{~nm}$. Los autores reportaron que es probable que el efecto de cavitación provocara el autoensamblado de residuos de las nanofibras que, posteriormente, dan como resultado las nanopartículas (Wijesena et al., 2015). Los citados reportes muestran resultados prometedores para producir nanopartículas de quitosano sin el uso de solventes y aditivos, permitiendo además preservar las propiedades estructurales de los materiales. Sin embargo, es necesario realizar investigaciones adicionales para demostrar que las estrategias de deconstrucción representan una alternativa real a las estrategias de construcción desde el punto de vista de su aplicación.

\section{Secado de nanopartículas de quitosano}

El secado de una suspensión de nanopartículas es una técnica útil que permite preservar y almacenar por determinados periodos de tiempo los sistemas, evitando su agregación y la perdida de estabilidad. Además, el secado permite también la generación de una estructura porosa en los materiales, con una importante área superficial y la incorporación de moléculas especificas en la estructura dependiendo de la metodología utilizada. Diversas técnicas se han empleado para llevar a cabo el secado de sistemas de nanopartículas, entre ellas el secado por aspersión, la liofilización y, recientemente, el secado supercrítico con $\mathrm{CO}_{2}$.

El secado por aspersión es una técnica útil para producir aglomerados, polvos o gránulos a partir de suspensiones poliméricas. Utilizando una corriente de aire caliente, la suspensión es atomizada permitiendo la recuperación de las partículas sólidas presentes en las pequeñas gotas del solvente en evaporación. El tamaño de partícula depende de parámetros tales como presión de atomización, la temperatura del aire de entrada, tamaño de la boquilla, el caudal de aspersión y el grado de entrecruzamiento. La Figura 5 muestra un esquema del procedimiento de secado por aspersión (Garg et al., 2016; Grenha et al., 2007; Huang et al., 2010; Ngan et al., 2014).

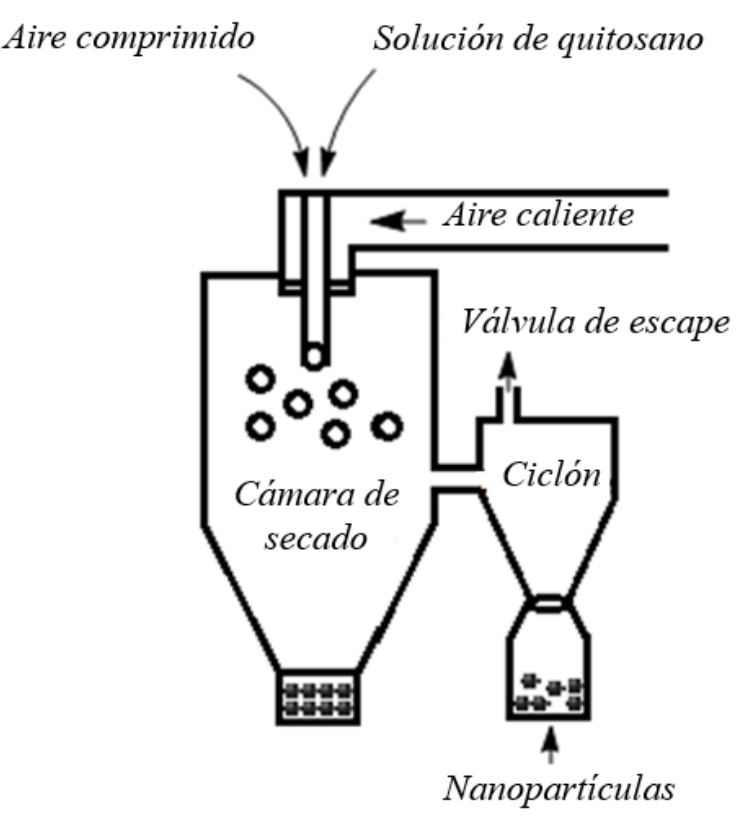

Figura 5. Procedimiento de secado por aspersión de nanopartículas. Figure 5. Spray drying nanoparticles procedure.

La liofilización es un método que permite la remoción de la fase solvente iniciando con el congelamiento de ésta, lo cual conlleva a la formación de cristales de hielo que en este caso actúan como porógenos y el control de su tamaño permitiría la obtención de materiales con tamaño de poro definido. Posteriormente el solvente es removido por sublimación mediante una reducción en la presión que provoca el cambio de sólido a gas sin pasar por líquido. La liofilización tiende a modificar la estructura de materiales previamente creados debido a la formación de los citados cristales de hielo que puede provocar un efecto de concentración de solutos. En consecuencia, se produce un número considerable de disrupciones y colapsos estructurales, lo que usualmente genera la producción de materiales formados por películas de xerogeles con estructuras macroporosas (Fonte et al., 2016; Franks, 1998; Mao et al., 2003).La metodología del secado con $\mathrm{CO}_{2}$ supercrítico $\left(\mathrm{scCO}_{2}\right)$ involucra la transferencia de masa entre un fluido en condiciones supercríticas y la fase solvente, lo cual da como resultado la presencia de poros en la estructura (Mehling et al., 2009; Nešić et al., 2018). Primeramente, el secado está predominantemente influenciado por una alta disolución de $\mathrm{scCO}_{2}$ en la fase solvente de la suspensión, lo que produce un líquido expandido y el derramamiento de éste fuera de la red polimérica. En segundo lugar, el contenido de la fase $\mathrm{scCO}_{2}$-solvente presente en los poros aumenta hasta que se alcanzan condiciones supercríticas sin prácticamente ninguna transición vapor-liquido intermedia previa. Finalmente, la presencia de mezclas de fluidos supercríticos en los poros conduce a la ausencia de tensión superficial, evitando así el fenómeno de colapso de los poros de la estructura de la red polimérica durante la eliminación del solvente. El quitosano ha sido empleado para la formación de materiales porosos obtenidos por secado de geles macroscópicos con $\mathrm{scCO}_{2}$ 
incorporando principios activos como ibuprofeno o paracetamol (Chang et al., 2008; Das et al., 2017; Ennajih et al., 2012; Mehling et al., 2009; Takeshita y Yoda, 2015). Recientemente, Caro-León et al., 2017 reportaron el secado con $\mathrm{scCO}_{2}$ de una suspensión de nanopartículas poliméricas de quitosano con tamaño promedio de $100 \mathrm{~nm}$. Los materiales presentaron un potencial zeta positivo mayor a $+30 \mathrm{mV}$ antes y después del secado (las nanopartículas fueron resuspendidas en medio acuoso después de ser secadas), lo que demostró la estabilidad de los sistemas. La estructura porosa obtenida permitió a dicho grupo de investigación la incorporación de la proteína $\beta$-lactoglobulina en las nanopartículas secas, a fin de generar un mecanismo de liberación controlada que permitiera potencializar las propiedades antioxidantes de dicha proteína (Caro-León et al., 2018).

\section{CONCLUSIONES}

Una gran variedad de métodos ha sido reportada para la obtención de nanopartículas de quitosano con la finalidad de optimizar sus propiedades, evitando cada vez más la utilización de solventes potencialmente tóxicos. Los próximos esfuerzos de los investigadores se centrarán en probar la aplicación de las nanopartículas de quitosano en medios cada vez más complejos, principalmente organismos vivos, lo que podría promover en un futuro su comercialización.

\section{AGRADECIMIENTOS}

Al CONACyT por su financiamiento al proyecto de ciencia básica CB-2011-01-169626 y por el otorgamiento de la beca DC2013-256 a FJCL. Al grupo de Investigación en Biopolímeros del Centro de Investigación en Alimentación y Desarrollo, A.C. Al Departamento de Investigación en Polímeros y Materiales de la Universidad de Sonora.

\section{REFERENCIAS}

Anitha, A., Deepa, N., Chennazhi, K.P., Lakshmanan, V.-K., Jayakumar, R. 2014. Combinatorial anticancer effects of curcumin and 5-fluorouracil loaded thiolated chitosan nanoparticles towards colon cancer treatment. Biochim. Biophys. Acta 1840, 2730-2743. https://doi.org/10.1016/j. bbagen.2014.06.004.

Anto-Shering, M., Kannan, C., Sabari Kumar, K., Sathish Kumar, V., Suganeshwari, M. 2011. Formulation of 5-fluorouracil Loaded Chitosan Nanoparticles By Emulsion Droplet Coalescence Method For Cancer Therapy. Int. J. Pharm. Biol. Arch. 2, 926-931.

Bagre, A.P., Jain, K., Jain, N.K. 2013. Alginate coated chitosan core shell nanoparticles for oral delivery of enoxaparin: in vitro and in vivo assessment. Int. J. Pharm. 456, 31-40. https://doi. org/10.1016/j.ijpharm.2013.08.037.

Barbari, G.R., Dorkoosh, F.A., Amini, M., Sharifzadeh, M., Atyabi, F., Balalaie, S., Rafiee Tehrani, N., Rafiee Tehrani, M. 2017. A novel nanoemulsion-based method to produce ultrasmall, water-dispersible nanoparticles from chitosan, surface modified with cell-penetrating peptide for oral delivery of proteins and peptides. Int. J. Nanomedicine 12, 3471-3483. https://doi.org/10.2147/IJN.S116063.
Bento, D., Staats, H.F., Gonçalves, T., Borges, O. 2015. Development of a novel adjuvanted nasal vaccine: $C 48 / 80$ associated with chitosan nanoparticles as a path to enhance mucosal immunity. Eur. J. Pharm. Biopharm. 93, 149-164. https://doi. org/10.1016/j.ejpb.2015.03.024.

Berthold, A., Cremer, K., Kreuter, J. 1996. Preparation and characterization of chitosan microspheres as drug carrier for prednisolone sodium phosphate as model for antiinflammatory drugs. J. Controlled Release 39, 17-25. https:// doi.org/10.1016/0168-3659(95)00129-8.

Birch, N.P., Schiffman, J.D. 2014. Characterization of selfassembled polyelectrolyte complex nanoparticles formed from chitosan and pectin. Langmuir 30, 3441-3447. https:// doi.org/10.1021/la500491c.

Borges, O., Borchard, G., Verhoef, J.C., de Sousa, A., Junginger, H.E. 2005. Preparation of coated nanoparticles for a new mucosal vaccine delivery system. Int. J. Pharm. 299, 155-166. https://doi.org/10.1016/j.ijpharm.2005.04.037.

Borges, O., Silva, M., de Sousa, A., Borchard, G., Junginger, H.E., Cordeiro-da-Silva, A. 2008. Alginate coated chitosan nanoparticles are an effective subcutaneous adjuvant for hepatitis B surface antigen. Int. Immunopharmacol. 8, 1773-1780. https://doi.org/10.1016/j.intimp.2008.08.013.

Bowman, K., Leong, K.W. 2006. Chitosan nanoparticles for oral drug and gene delivery. Int. J. Nanomedicine 1, 117-128.

Bravo-Osuna, I., Vauthier, C., Farabollini, A., Palmieri, G.F., Ponchel, G. 2007. Mucoadhesion mechanism of chitosan and thiolated chitosan-poly(isobutyl cyanoacrylate) coreshell nanoparticles. Biomaterials 28, 2233-2243. https://doi. org/10.1016/j.biomaterials.2007.01.005.

Calvo, P., Remuñán-López, C., Vila-Jato, J.L., Alonso, M.J. 1997. Novel hydrophilic chitosan-polyethyleneoxidenanoparticles as protein carriers. J. Appl. Polym. Sci. 63, 125-132. https:// doi.org/10.1002/(SICI)1097-4628(19970103)63:1<125::AIDAPP13>3.0.CO;2-4.

Canelas, D.A., Herlihy, K.P., DeSimone, J.M. 2009. Top-down particle fabrication: control of size and shape for diagnostic imaging and drug delivery. Wiley Interdiscip. Rev. Nanomed. Nanobiotechnol. 1, 391-404. https://doi.org/10.1002/ wnan.40.

Caro-León, F.J., Lizardi-Mendoza, J., Argüelles-Monal, W., Carvajal-Millan, E., Franco, Y.L.L., Goycoolea, F.M. 2017. Supercritical $\mathrm{CO}_{2}$ dried chitosan nanoparticles: production and characterization. RSC Adv. 7, 30879-30885. https://doi. org/10.1039/C7RA02555F.

Caro-León, F.J., Argüelles-Monal, W., Carvajal-Millán, E., LópezFranco, Y.L., Goycoolea-Valencia, F.M., San Román del Barrio, J., Lizardi-Mendoza, J. 2018. Production and characterization of supercritical $\mathrm{CO}_{2}$ dried chitosan nanoparticles as novel carrier device. Carbohydr. Polym. 198, 556-562. https://doi. org/10.1016/j.carbpol.2018.06.102.

Cavalli, R., Leone, F., Minelli, R., Fantozzi, R., Dianzani, C. 2014. New Chitosan Nanospheres for the Delivery of 5-Fluorouracil: Preparation, Characterization and in vitro Studies. Curr. Drug Deliv. 11, 270-278. https://doi.org/10.2174/1567201811666 140206103609.

Chang, X., Chen, D., Jiao, X. 2008. Chitosan-Based Aerogels with High Adsorption Performance. J. Phys. Chem. B 112, 7721-7725. https://doi.org/10.1021/jp8011359.

Chantarasataporn, P., Tepkasikul, P., Kingcha, Y., Yoksan, R., Pichyangkura, R., Visessanguan, W., Chirachanchai, S. 2014. 
Water-based oligochitosan and nanowhisker chitosan as potential food preservatives for shelf-life extension of minced pork. Food Chem. 159, 463-470. https://doi. org/10.1016/j.foodchem.2014.03.019.

Chua, B.Y., Al Kobaisi, M., Zeng, W., Mainwaring, D., Jackson, D.C. 2012. Chitosan microparticles and nanoparticles as biocompatible delivery vehicles for peptide and proteinbased immunocontraceptive vaccines. Mol. Pharm. 9, 81-90. https://doi.org/10.1021/mp200264m.

Das, S., Heasman, P., Ben, T., Qiu, S. 2017. Porous Organic Materials: Strategic Design and Structure-Function Correlation. Chem. Rev. 117, 1515-1563. https://doi.org/10.1021/acs. chemrev.6b00439.

de la Fuente, M., Seijo, B., Alonso, M.J. 2008. Novel hyaluronic acid-chitosan nanoparticles for ocular gene therapy. Invest. Ophthalmol.Vis. Sci.49, 2016-2024. https://doi.org/10.1167/ iovs.07-1077.

Delair, T. 2011. Colloidal polyelectrolyte complexes of chitosan and dextran sulfate towards versatile nanocarriers of bioactive molecules. Eur. J. Pharm. Biopharm. Off. J. Arbeitsgemeinschaft Für Pharm. Verfahrenstechnik EV 78, 10-18. https://doi.org/10.1016/j.ejpb.2010.12.001.

Divya, K., Jisha, M.S. 2018. Chitosan nanoparticles preparation and applications. Environ. Chem. Lett. 16, 101-112. https:// doi.org/10.1007/s10311-017-0670-y.

El-Shabouri, M.H. 2002. Positively charged nanoparticles for improving the oral bioavailability of cyclosporin-A. Int. J. Pharm. 249, 101-108.

Ennajih, H., Bouhfid, R., Essassi, E.M., Bousmina, M., El Kadib, A. 2012. Chitosan-montmorillonite bio-based aerogel hybrid microspheres. Microporous Mesoporous Mater. 152, 208-213. https://doi.org/10.1016/j.micromeso.2011.11.032.

Fonte, P., Reis, S., Sarmento, B. 2016. Facts and evidences on the lyophilization of polymeric nanoparticles for drug delivery. J. Controlled Release 225, 75-86. https://doi.org/10.1016/j. jconrel.2016.01.034.

Franks, F. 1998. Freeze-drying of bioproducts: putting principles into practice. Eur. J. Pharm. Biopharm. 45, 221-229. https:// doi.org/10.1016/S0939-6411(98)00004-6.

Fülöp, Z., Saokham, P., Loftsson, T. 2014. Sulfobutylether- $\beta$ cyclodextrin/chitosan nano- and microparticles and their physicochemical characteristics. Int. J. Pharm. 472, 282-287. https://doi.org/10.1016/j.ijpharm.2014.06.039.

Garcia-Fuentes, M., Alonso, M.J. 2012. Chitosan-based drug nanocarriers: where do we stand? J. Control. Release Off. J. Control. Release Soc. 161, 496-504. https://doi. org/10.1016/j.jconrel.2012.03.017.

Garg, T., Rath, G., Goyal, A.K. 2016. Inhalable chitosan nanoparticles as antitubercular drug carriers for an effective treatment of tuberculosis. Artif. Cells Nanomedicine Biotechnol. 44, 997-1001. https://doi.org/10.3109/2169140 1.2015.1008508.

Ge, H., Hua, T., Chen, X. 2016. Selective adsorption of lead on grafted and crosslinked chitosan nanoparticles prepared by using $\mathrm{Pb}^{2+}$ as template. J. Hazard. Mater. 308, 225-232. https://doi.org/10.1016/j.jhazmat.2016.01.042.

Goycoolea, F.M., Lollo, G., Remuñán-López, C., Quaglia, F., Alonso, M.J. 2009. Chitosan-Alginate Blended Nanoparticles as Carriers for the Transmucosal Delivery of Macromolecules. Biomacromolecules 10, 1736-1743. https://doi.org/10.1021/ bm9001377.
Grenha, A., Seijo, B., Serra, C., Remuñan-López, C. 2007. Chitosan nanoparticle-loaded mannitol microspheres: structure and surface characterization. Biomacromolecules 8, 2072-2079. https://doi.org/10.1021/bm061131g.

Grenha, A., Gomes, M.E., Rodrigues, M., Santo, V.E., Mano, J.F., Neves, N.M., Reis, R.L. 2010. Development of new chitosan/ carrageenan nanoparticles for drug delivery applications. J. Biomed. Mater. Res. A 92A, 1265-1272. https://doi. org/10.1002/jbm.a.32466.

Grenha, A. 2012. Chitosan nanoparticles: a survey of preparation methods. J. Drug Target. 20, 291-300. https://doi.org/10.310 9/1061186X.2011.654121.

Hood, M.A., Landfester, K., Muñoz-Espí, R. 2018. Chitosan nanoparticles affect polymorph selection in crystallization of calcium carbonate. Colloids Surf. Physicochem. Eng. Asp. 540, 48-52. https://doi.org/10.1016/j.colsurfa.2017.12.048.

Hu, Y., Jiang, X., Ding, Y., Ge, H., Yuan, Y., Yang, C. 2002. Synthesis and characterization of chitosan-poly(acrylic acid) nanoparticles. Biomaterials 23, 3193-3201. https://doi. org/10.1016/S0142-9612(02)00071-6.

Huang, H.-Y., Shieh, Y.-T., Shih, C.-M., Twu, Y.-K. 2010. Magnetic chitosan/iron (II, III) oxide nanoparticles prepared by spray-drying. Carbohydr. Polym. 81, 906-910. https://doi. org/10.1016/j.carbpol.2010.04.003.

Jain, A., Thakur, K., Kush, P., Jain, U.K. 2014. Docetaxel loaded chitosan nanoparticles: formulation, characterization and cytotoxicity studies. Int. J. Biol. Macromol. 69, 546-553. https://doi.org/10.1016/j.jjbiomac.2014.06.029.

Jiang, L., Duan, H., Ji, X., Wang, T., Wang, Y., Qiu, J. 2018. Application of a simple desolvation method to increase the formation yield, physical stability and hydrophobic drug encapsulation capacity of chitosan-based nanoparticles. Int. J. Pharm. 545, 117-127. https://doi.org/10.1016/j.ijpharm.2018.03.044.

Kim, T.-H., Jiang, H.-L., Jere, D., Park, I.-K., Cho, M.-H., Nah, J.-W., Choi, Y.-J., Akaike, T., Cho, C.-S. 2007. Chemical modification of chitosan as a gene carrier in vitro and in vivo. Prog. Polym. Sci. 32, 726-753. https://doi.org/10.1016/j. progpolymsci.2007.05.001.

Kim, J.-H., Kim, Y.-S., Park, K., Lee, S., Nam, H.Y., Min, K.H., Jo, H.G., Park, J.H., Choi, K., Jeong, S.Y., Park, R.-W., Kim, I.-S., Kim, K., Kwon, I.C. 2008. Antitumor efficacy of cisplatin-loaded glycol chitosan nanoparticles in tumor-bearing mice. J. Controlled Release 127, 41-49. https://doi.org/10.1016/j. jconrel.2007.12.014.

Kumar, N., Parthiban, S., Kumar, G.S., Mani, T.T. 2016. Ocular Drug Delivery of Levofloxacin Loaded Chitosan Nanoparticle by Emulsion Solvent Diffusion Method. Imp. J. Interdiscip. Res. 2.

Lavertu, M., Méthot, S., Tran-Khanh, N., Buschmann, M.D. 2006. High efficiency gene transfer using chitosan/DNA nanoparticles with specific combinations of molecular weight and degree of deacetylation. Biomaterials 27, 48154824. https://doi.org/10.1016/j.biomaterials.2006.04.029.

Li, F., Li, J., Wen, X., Zhou, S., Tong, X., Su, P., Li, H., Shi, D. 2009. Antitumor activity of paclitaxel-loaded chitosan nanoparticles: An in vitro study. Mater. Sci. Eng. C 29, 2392-2397. https:// doi.org/10.1016/j.msec.2009.07.001.

Liang, J., Cao, L., Zhang, L., Wan, X.-C. 2014. Preparation, characterization, and in vitro antitumor activity of folate conjugated chitosan coated EGCG nanoparticles. Food Sci. Biotechnol. 23, 569-575. https://doi.org/10.1007/s10068014-0078-4. 
Liu, D., Chang, P.R., Chen, M., Wu, Q. 2011. Chitosan colloidal suspension composed of mechanically disassembled nanofibers. J. Colloid Interface Sci. 354, 637-643. https://doi. org/10.1016/j.jcis.2010.11.041.

Liu, Q., Zheng, X., Zhang, C., Shao, X., Zhang, X., Zhang, Q., Jiang, X. 2014. Antigen-conjugated $\mathrm{N}$-trimethylaminoethylmethacrylate Chitosan Nanoparticles Induce Strong Immune Responses After Nasal Administration. Pharm. Res. 32, 22-36. https://doi. org/10.1007/s11095-014-1441-0.

Luque-Alcaraz, A.G., Lizardi, J., Goycoolea, F.M., Valdez, M.A., Acosta, A.L., Iloki-Assanga, S.B., Higuera-Ciapara, I., ArgüellesMonal, W. 2012. Characterization and Antiproliferative Activity of Nobiletin-Loaded Chitosan Nanoparticles. J. Nanomater. 2012. https://doi.org/10.1155/2012/265161.

Mali, N., Wavikar, P., Vavia, P. 2015. Serratiopeptidase loaded chitosan nanoparticles by polyelectrolyte complexation: in vitro and in vivo evaluation. AAPS PharmSciTech 16, 59-66. https://doi.org/10.1208/s12249-014-0201-0.

Mao, H.Q., Roy, K., Troung-Le, V.L., Janes, K.A., Lin, K.Y., Wang, Y., August, J.T., Leong, K.W. 2001. Chitosan-DNA nanoparticles as gene carriers: synthesis, characterization and transfection efficiency. J. Control. Release Off. J. Control. Release Soc. 70, 399-421.

Mao, J.S., Zhao, L.G., Yin, Y.J., Yao, K.D. 2003. Structure and properties of bilayer chitosan-gelatin scaffolds. Biomaterials 24, 1067-1074. https://doi.org/10.1016/S01429612(02)00442-8.

Martínez-Rivas, C.J., Tarhini, M., Badri, W., Miladi, K., GreigeGerges, H., Nazari, Q.A., Galindo Rodríguez, S.A., Román, R.Á., Fessi, H., Elaissari, A. 2017. Nanoprecipitation process: From encapsulation to drug delivery. Int. J. Pharm. 532, 66-81. https://doi.org/10.1016/j.ijpharm.2017.08.064.

Mehling, T., Smirnova, I., Guenther, U., Neubert, R.H.H. 2009. Polysaccharide-based aerogels as drug carriers. J. NonCryst. Solids 355, 2472-2479. https://doi.org/10.1016/j. jnoncrysol.2009.08.038.

Mitra, S., Gaur, U., Ghosh, P.C., Maitra, A.N. 2001. Tumour targeted delivery of encapsulated dextran-doxorubicin conjugate using chitosan nanoparticles as carrier. J. Control. Release Off. J. Control. Release Soc. 74, 317-323.

Nam, J.-P., Choi, C., Jang, M.-K., Jeong, Y.-I., Nah, J.-W., Kim, S.-H., Park, Y. 2010. Insulin-incorporated chitosan nanoparticles based on polyelectrolyte complex formation. Macromol. Res. 18, 630-635. https://doi.org/10.1007/s13233-010-07147.

Nešić, A., Gordić, M., Davidović, S., Radovanović, Ž., Nedeljković, J., Smirnova, I., Gurikov, P. 2018. Pectin-based nanocomposite aerogels for potential insulated food packaging application. Carbohydr. Polym. 195, 128-135. https://doi.org/10.1016/j. carbpol.2018.04.076.

Ngan, L.T.K., Wang, S.-L., Hiep, Đ.M., Luong, P.M., Vui, N.T., Đinh, T.M., Dzung, N.A. 2014. Preparation of chitosan nanoparticles by spray drying, and their antibacterial activity. Res. Chem. Intermed. 40, 2165-2175. https://doi.org/10.1007/s11164014-1594-9.

Niwa, T., Takeuchi, H., Hino, T., Kunou, N., Kawashima, Y. 1994. In vitro drug release behavior of D,L-lactide/glycolide copolymer (PLGA) nanospheres with nafarelin acetate prepared by a novel spontaneous emulsification solvent diffusion method. J. Pharm. Sci. 83, 727-732.
Ohya, Y., Shiratani, M., Kobayashi, H., Ouchi, T. 1994. Release Behavior of 5-Fluorouracil from Chitosan-Gel Nanospheres Immobilizing 5-Fluorouracil Coated with Polysaccharides and Their Cell Specific Cytotoxicity. J. Macromol. Sci. Part A 31, 629-642. https://doi.org/10.1080/10601329409349743.

Orellano, M.S., Porporatto, C., Silber, J.J., Falcone, R.D., Correa, N.M. 2017. AOT reverse micelles as versatile reaction media for chitosan nanoparticles synthesis. Carbohydr. Polym. 171, 85-93. https://doi.org/10.1016/j.carbpol.2017.04.074

Pereira, A.G.B., Muniz, E.C., Hsieh, Y.-L. 2014. Chitosan-sheath and chitin-core nanowhiskers. Carbohydr. Polym. 107, 158-166. https://doi.org/10.1016/j.carbpol.2014.02.046.

Piñón-Segundo, E., Llera-Rojas, V.G., Leyva-Gómez, G., UrbánMorlán, Z., Mendoza-Muñoz, N., Quintanar-Guerrero, D. 2018. Chapter 2 - The emulsification-diffusion method to obtain polymeric nanoparticles: Two decades of research, in: Grumezescu, A.M. (Ed.), Nanoscale Fabrication, Optimization, Scale-Up and Biological Aspects of Pharmaceutical Nanotechnology. William Andrew Publishing, pp. 51-83. https://doi.org/10.1016/B978-0-12-813629-4.00002-4.

Raj, R., Wairkar, S., Sridhar, V., Gaud, R. 2018. Pramipexole dihydrochloride loaded chitosan nanoparticles for nose to brain delivery: Development, characterization and in vivo anti-Parkinson activity. Int. J. Biol. Macromol. 109, 27-35. https://doi.org/10.1016/j.ijbiomac.2017.12.056.

Riegger, B.R., Bäurer, B., Mirzayeva, A., Tovar, G.E.M., Bach, M. 2018. A systematic approach of chitosan nanoparticle preparation via emulsion crosslinking as potential adsorbent in wastewater treatment. Carbohydr. Polym. 180, 46-54. https://doi.org/10.1016/j.carbpol.2017.10.002.

Rinaudo, M., 2006. Chitin and chitosan: Properties and applications. Prog. Polym. Sci. 31, 603-632. https://doi. org/10.1016/j.progpolymsci.2006.06.001.

Rodrigues, S., Dionísio, M., López, C.R., Grenha, A. 2012. Biocompatibility of Chitosan Carriers with Application in Drug Delivery. J. Funct. Biomater. 3, 615-641. https://doi. org/10.3390/jfb3030615.

Shaker, M.A. 2015. Adsorption of $\mathrm{Co}(\mathrm{II}), \mathrm{Ni}(\mathrm{II})$ and $\mathrm{Cu}(\mathrm{II})$ ions onto chitosan-modified poly(methacrylate) nanoparticles: Dynamics, equilibrium and thermodynamics studies. J. Taiwan Inst. Chem. Eng. 57, 111-122. https://doi. org/10.1016/j.jtice.2015.05.027.

Silva, M.M., Calado, R., Marto, J., Bettencourt, A., Almeida, A.J., Gonçalves, L.M.D. 2017. Chitosan Nanoparticles as a Mucoadhesive Drug Delivery System for Ocular Administration. Mar. Drugs 15, 370. https://doi.org/10.3390/ md15120370.

Sullivan, D.J., Cruz-Romero, M., Collins, T., Cummins, E., Kerry, J.P., Morris, M.A. 2018. Synthesis of monodisperse chitosan nanoparticles. Food Hydrocoll. 83, 355-364. https://doi. org/10.1016/j.foodhyd.2018.05.010.

Takeshita, S., Yoda, S., 2015. Chitosan Aerogels: Transparent, Flexible Thermal Insulators. Chem. Mater. 27, 7569-7572. https://doi.org/10.1021/acs.chemmater.5b03610.

Tian, X.X., Groves, M.J., 1999. Formulation and biological activity of antineoplastic proteoglycans derived from Mycobacterium vaccae in chitosan nanoparticles. J. Pharm. Pharmacol. 51, 151-157.

Tokumitsu, H., Ichikawa, H., Fukumori, Y. 1999. ChitosanGadopentetic Acid Complex Nanoparticles for Gadolinium Neutron-Capture Therapy of Cancer: Preparation by 
Novel Emulsion-Droplet Coalescence Technique and Characterization. Pharm. Res. 16, 1830-1835. https://doi. org/10.1023/A:1018995124527.

Vimal, S., Abdul Majeed, S., Taju, G., Nambi, K.S.N., Sundar Raj, N., Madan, N., Farook, M.A., Rajkumar, T., Gopinath, D., Sahul Hameed, A.S. 2013. Chitosan tripolyphosphate (CS/TPP) nanoparticles: Preparation, characterization and application for gene delivery in shrimp. Acta Trop. 128, 486-493. https:// doi.org/10.1016/j.actatropica.2013.07.013.

Wang, Q., Zhao, Y., Guan, L., Zhang, Y., Dang, Q., Dong, P., Li, J., Liang, X. 2017. Preparation of astaxanthin-loaded DNA/ chitosan nanoparticles for improved cellular uptake and antioxidation capability. Food Chem. 227, 9-15. https://doi. org/10.1016/j.foodchem.2017.01.081.

Watzke, H.J., Dieschbourg, C. 1994. Novel silica-biopolymer nanocomposites: the silica sol-gel process in biopolymer organogels. Adv. Colloid Interface Sci. 50, 1-14. https://doi. org/10.1016/0001-8686(94)80021-9.

Wijesena, R.N., Tissera, N., Kannangara, Y.Y., Lin, Y., Amaratunga,
G.A.J., de Silva, K.M.N. 2015. A method for top down preparation of chitosan nanoparticles and nanofibers. Carbohydr. Polym. 117, 731-738. https://doi.org/10.1016/j. carbpol.2014.10.055.

Zhang, W., Li, J., Zhang, J., Sheng, J., He, T., Tian, M., Zhao, Y., Xie, C., Mai, L., Mu, S. 2017. Top-Down Strategy to Synthesize Mesoporous Dual Carbon Armored MnO Nanoparticles for Lithium-Ion Battery Anodes. ACS Appl. Mater. Interfaces 9, 12680-12686. https://doi.org/10.1021/acsami.6b16576.

Zhi, J., Wang, Y., Lu, Y., Ma, J., Luo, G., 2006. In situ preparation of magnetic chitosan/ $/ \mathrm{Fe}_{3} \mathrm{O}_{4}$ composite nanoparticles in tiny pools of water-in-oil microemulsion. React. Funct. Polym. 66, 1552-1558. https://doi.org/10.1016/j. reactfunctpolym.2006.05.006.

Zhou, Y., Liu, S., Peng, H., Yu, L., He, B., Zhao, Q. 2015. In vivo anti-apoptosis activity of novel berberine-loaded chitosan nanoparticles effectively ameliorates osteoarthritis. Int. Immunopharmacol. 28, 34-43. https://doi.org/10.1016/j. intimp.2015.05.014. 